\title{
ПЕРВИЧНАЯ НАДПОЧЕЧНИКОВАЯ НЕДОСТАТОЧНОСТЬ: УРОКИ ОТ COVID-19
}

\author{
Волкова Н.И., Решетников И.Б.
}

ФГБОУ ВО Ростовский государственный медицинский университет Минздрава России

В марте 2020 года SARS-CoV-2, причина COVID-19, достиг уровня пандемии с высоким уровнем глобальной смертности. Поразительной особенностью COVID-19 является его способность поражать несколько систем органов. Вирус COVID-19 использует белок на своей поверхности, который связывается с рецептором типа ACE2, чтобы проникать в клетки тела инфицированного человека. ACE2 присутствует во многих типах клеток и тканях, включая легкие, сердце, кровеносные сосуды, почки, печень и желудочно-кишечный тракт. Он также экспрессируется на артериальных и венозных эндотелиальных клетках многих органов, включая надпочечники. В легких он помогает расщеплять гормон ангиотензин II на другой гормон ангиотензин I. Когда вирус SARS-CoV-2 связывается с ACE2, он не позволяет ACE2 регулировать передачу сигналов ангиотензина II, делая больше ангиотензина II доступным для поврежденных тканей. Легкие являются основным местом поражения инфекцией SARS-CoV-2, что увеличивает риск острого респираторного дистресс-синдрома. Тем не менее его влияние на эндокринную систему до конца не выяснено, и данные о динамике кортизола у пациентов с COVID-19 пока отсутствуют. Вероятно, SARS-CoV-2 может подавить ответ на стрессовую реакцию организма через кортизол.

КЛИНИЧЕСКИЙ СЛУЧАЙ. Женщина 38 лет доставлена в приемное отделение больницы с двумя эпизодами рвоты. Других жалоб она не предъявляла, а также отрицала наличие жар, боль в животе, диарею или любые другие связанные с этим симптомы.

За две недели до этого был выявлен положительный результат на COVID-19, однако, учитывая бессимптомное течение и нормальные лабораторные и рентгенологические показатели, пациентка была помещена домашний карантин. Данные анамнеза не представляют значимого интереса.

При физикальном обследовании отмечалась гипотония (85/60 мм рт.ст.) ЧСС 75 уд/мин, ЧДД 15 в мин. Сатурация атмосферным воздухом 98\%. Изменение окраски кожи и слизистых оболочек не было обнаружено, как и признаков изменения массы тела.

Данные лабораторных исследований показали лейкопению (3,3×109/л) и нормоцитарную нормохромную анемию (Hb 98 г/л). Значительные нарушения электролитного баланса (гипонатриемия, гипохлоремия, гипомагниемия, гипофосфатемия и низко-нормальный уровень калия) с развитем метаболического ацидоза (Ph 7.28). Гормональные обследования показали нормальный уровень ТТГ (2.2 ME/Л). Низкий базальный уровень кортизола 127 нмоль/л, и высокий уровень АКТГ 78пг/мл. Данные предыдущих обследований отсутствовали.

У нашей пациентки была гипотоническая гипонатриемия с гипохлоремией и метаболическим ацидозом, которые нельзя было объяснить симптомами только двух эпизодов рвоты и обезвоживания, что совместно с низким базальным уровнем кортизола, наводит нас на мысль о наличии первичной надпочечниковой недостаточности. Пациентке начата регидратационная терапия и назначен преднизолон в дозировке 20мг/сут, что привело к нормализации уровня натрия, артериального давления и общего самочувствия. На 10-й день состояние улучшилось, и после двух отрицательных результатов ПЦР на COVID-19 она была выписана на 10 мг преднизолона в день с последующим эндокринологическим наблюдением в амбулаторных условиях. К сожалению, пациентка не явился на контрольный прием, поэтому полное эндокринологическое обследование не проводилось. Основной окончательный диагноз: COVID-19, осложнение основного: первичная надпочечниковая недостаточность.

ВЫВоды: COVID-19 может вызвать острую адренокортикальную недостаточность, влияя на ось гипоталамус - гипофиз - надпочечники. Данных о динамике кортизола у пациентов C COVID-19 пока нет. Тем не менее клиницисты должны быть бдительны в отношении возможности лежащего в основе относительного дефицита кортизола у пациентов с COVID-19. 